\title{
El ingreso a la universidad de jóvenes en situación de vulnerabilidad social: razones y factores que los motivan
}

Leticia Cerezo

\section{RESUMEN}

Los procesos de masificación de la educación superior que tuvieron lugar en Argentina posibilitaron procesos de democratización del acceso a la educación superior universitaria, pero no han logrado una democratización cualitativa en tanto persisten desigualdades sociales como condicionantes de las trayectorias educativas. En este texto nos interesa aportar conocimiento vinculado al ingreso de jóvenes en situación de vulnerabilidad social a las universidades públicas, desde un enfoque principalmente cualitativo. Específicamente en torno a las principales motivaciones aducidas por los jóvenes respecto de su ingreso a la universidad y a los factores que incidieron en la elección de estudiar en una institución determinada.

Palabras clave: educación superior universitaria, universidades públicas, ingreso, sectores vulnerables, Argentina. Ciencias Sociales (FLACSO), Sede Argentina. Becaria Doctoral Consejo Nacional de Investigaciones Científicas y Técnicas (CONICET) por el Centro de Innovación de los Trabajadores (CITRA), Universidad Metropolitana para la Educación y el Trabajo (UMET), Argentina. Temas de investigación: educación superior, inclusión educativa, políticas sociales, trayectorias educativas. 


\section{A entrada na universidade de jovens em situação de vulnerabilidade social: razões e fatores que os motivam}

\section{RESUMO}

Os processos de massificação da educação superior que aconteceram na Argentina possibilitaram processos de democratização do acesso à educação superior universitária, mas não tem alcançado uma democratização qualitativa, já que persistem desigualdades sociais como condicionantes das trajetórias educativas. Neste texto nos interessa contribuir com conhecimento vinculado a entrada de jovens em situação de vulnerabilidade social às universidades públicas, desde um enfoque principalmente qualitativo. Especificamente em torno das principais motivações aduzidas pelos jovens com respeito a sua entrada à universidade e aos fatores que incidiram na eleição de estudar em uma instituição determinada.

Palavras chave: educação superior universitária, universidades públicas, entrada, setores vulneráveis, Argentina.

The entrance to the university of young people in situation of social vulnerability: reasons and factors that motivate them

\section{ABSTRACT}

The processes of expansion of higher education that took place in Argentina made it possible to democratize the access to university higher education, but they have not achieved qualitative democratization while social inequalities persist as conditioning factors of the educational trajectories. In this article the authors are interested in providing knowledge related to the entrance of young people in situations of social vulnerability to public universities, from a mainly qualitative approach. They specifically deal with the main motivations adduced by young people regarding their admission to the university and the factors that influenced the choice of studying in a given institution.

Key words: university higher education, public universities, income, vulnerable sectors, Argentina.

Recepción: 31/05/16. Aprobación: 29/05/17. 


\section{Introducción}

El sistema universitario argentino ha experimentado, en consonancia con las transformaciones que se dieron tanto en América Latina como a nivel mundial, procesos de masificación. Diversas variables han contribuido y contribuyen a la ampliación de las bases de reclutamiento de estudiantes universitarios en nuestro país. Entre ellas cabe referir a la gratuidad de la enseñanza superior como marco de referencia habilitante (Carli, 2012; García de Fanelli, 2005); el ingreso mayoritariamente irrestricto (Carli, 2012; Chiroleu, 2013; Sigal, 1995; Toribio, 2010); las políticas educativas de ampliación de la oferta - "olas de fundación" de las instituciones en términos de Chiroleu y Marquina (2012) - ; la mayor cobertura en el nivel medio incentivada en gran medida por su obligatoriedad y universalización (Dussel, 2010; Sigal, 1995), y las expectativas y pretensiones de ascenso y movilidad social ascendente estructuradas en torno a la adquisición de capital educativo (Carli, 2012; Dussel, 2005; Mayer, 2012; Sigal, 1995; Tiramonti y Montes, 2008; Tiramonti y Ziegler, 2008).

Estos procesos de masificación en las universidades argentinas, que hasta entrado el siglo XX eran habitadas por grupos de élite exclusivamente (Buchbinder, 2005; Carli, 2012; Hernández y Garbarini, 2010; Veleda, 2002), permitió en primera instancia la incorporación de estudiantes de clase media (Carli, 2012; Hernández y Garbarini, 2010) y mucho más recientemente la incorporación de jóvenes pertenecientes a estratos sociales bajos (Carli, 2012; Chiroleu, 2013; Pochulu, 2004; Tiramonti y Ziegler, 2008; Toribio, 2010).

Diversos indicadores contribuyen a apreciar la ampliación de las bases de reclutamiento de las universidades. Uno de ellos es el análisis de la tendencia de la matrícula universitaria en términos absolutos. Tal como se desprende de la gráfica 1, observamos que la matrícula de estudiantes de educación superior universitaria, aunque con variaciones vinculadas a los distintos proyectos de política educativa, aumentó en un siglo de manera exponencial. Otra es la tasa bruta de escolarización universitaria: ${ }^{1}$ en 1980 esta tasa era para de la población de 18 a 24 años de 13.5\% (CEPAL, 1992) y treinta años después ya presentaba un valor de $37.8 \%$ (SPU, 2011). Es posible afirmar entonces que Argentina transitó en muy poco tiempo desde el modelo de acceso de élites - la Tasa Brutal de Matrícula (TBM) es inferior al 15\% - hacia un modelo de acceso universal - implica que la TBM supera el 35\%- (Brunner, 2012; Sigal, 1995).

Cabe referir que en las transformaciones experimentadas en la composición de los estudiantes del nivel superior universitario mucho tuvieron que ver las políticas educativas implementadas en Argentina y sus consecuentes implicaciones en el crecimiento o reducción de la matrícula universitaria, políticas que si bien exceden el análisis del presente artículo, no pueden dejar de ser mencionadas a los fines de comprender las dinámicas y contextualizar el sistema educativo superior universitario. ${ }^{2}$ La masificación universitaria, si bien posibilitó el ingreso de bases sociales más amplias de estudiantes a las instituciones universitarias, entraña brechas según la clase social (Ezcurra, 2009) y no garantizó la permanencia de todos los jóvenes por igual.

En relación con las diferencias en la composición social de los ingresantes a la universidad, Chiroleu (2013) analiza, a partir de datos del Sistema de

\footnotetext{
${ }^{1}$ Para la definición de este indicador hemos tomado la definición de la UNESCO (2009). La Tasa Bruta de Matrícula Universitaria (TBM) corresponde a la proporción entre el número de personas matriculadas en nivel de enseñanza superior universitario, independientemente de su edad, sobre la población del grupo de edad teórica correspondiente a ese nivel de enseñanza, en nuestro caso de 18 a 24 años de edad. Cabe referir que la TBM es un indicador que mide de forma aproximada el acceso a un determinado nivel de enseñanza en tanto puede sobreestimar o subestimar el grado en que la población es atendida por ese nivel (Mendoza Rojas, 2015).

${ }^{2}$ Para analizar este fenómeno con una perspectiva histórica véase, entre otros, Buchbinder, 2005; Chiroleu y Marquina, 2012, y Hernández y Garbarini, 2010.
} 


\section{Gráfica 1. Matrícula universitaria total* en Argentina. Años 1910-2011}

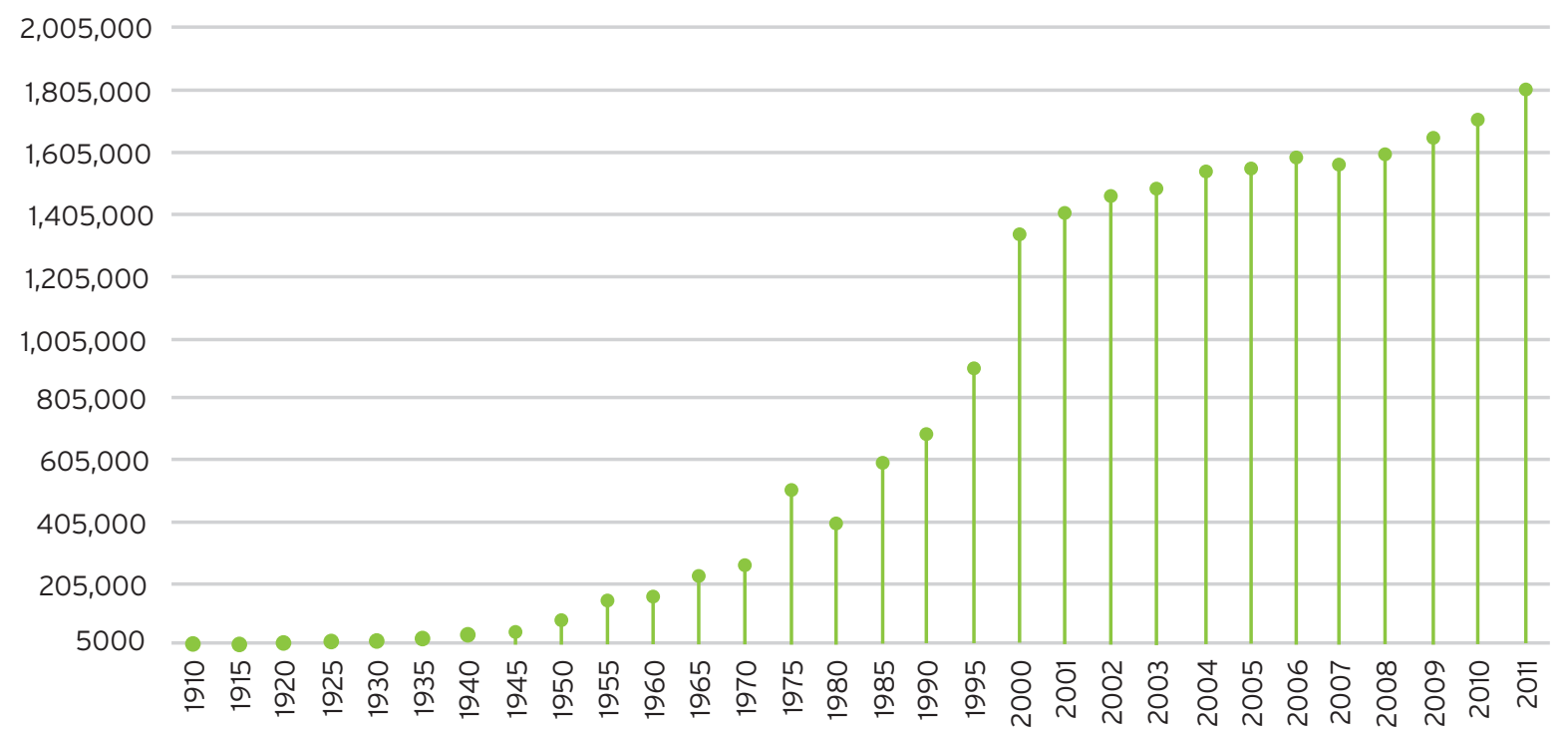

* Incluye matrícula de universidades de gestión estatal y privada.

Fuentes: años 1910 a 1995: Toribio (2010). Años 2000 a 2011: Anuario de Estadísticas Educativas, Secretaría de Políticas Universitarias, Ministerio de Educación, Argentina.

Información de Tendencias Educativas en América Latina (SITEAL) construidos con base en la Encuesta Permanente de Hogares del INDEC de 2010, las trayectorias educativas según nivel socioeconómico buscando identificar las posibles brechas entre niveles socioeconómicos altos y bajos. La autora indica que el porcentaje de jóvenes de entre 20 y 21 años de edad que se encontraban escolarizados en el nivel superior en 2010 era de 39\% en Argentina, descendiendo a 18\% entre los jóvenes pertenecientes al grupo socioeconómico más bajo y ascendiendo a $66 \%$ entre los de nivel más alto.

Respecto de la graduación y el modo en que las desigualdades sociales se imbrican en los indicadores que dan cuenta de ella, en 2013 la proporción de egresados universitarios sobre el total de universitarios de 18 a 30 años era de 17\%, presentando una brecha importante en el logro del título entre aquellos pertenecientes a hogares de mayores ingresos, entre quienes ascendía a 36\%, y los de menores ingresos, con un 6\% (García de Fanelli, 2015).

De allí que sea posible afirmar que, si bien se ha democratizado el ingreso a la universidad, subsisten formas de desigualdad en la permanencia y graduación de los estudiantes universitarios (García de Fanelli, 2005 y 2015; Panaia, 2013, y Uthoff y Beccaria, 2007). Es decir, no se ha logrado debilitar efectivamente el lazo entre los orígenes sociales y el destino escolar - democratización cualitativa en términos de Prost (1986)-. Refiriéndose también a las desiguales probabilidades de graduación entre los distintos sectores sociales, Ezcurra (2011) sostiene que en las universidades tiene lugar una "inclusión excluyente" - noción que es retomada por distintos autores (Fernández Lamarra, 2015; Progré, 2015, entre otros) - que consiste en una tendencia al fracaso académico y al abandono de sus estudios de estudiantes pertenecientes a franjas sociales que se 
encuentran en desventaja respecto de la distribución del capital económico y cultural.

En este punto resulta de interés incluir en nuestro marco conceptual la noción de trayectoria educativa, ya que nos permite vincular el contexto estructural al que hemos hecho referencia con el plano subjetivo, aportando a problematizar y comprender las desigualdades de permanencia y graduación. La noción de trayectoria educativa nos habilita a articular en un mismo concepto las elecciones de los sujetos, las experiencias familiares, las propuestas institucionales disponibles, así como también su contexto social que opera condicionando sus recorridos y prácticas (Montes y Sendón, 2010). En otras palabras, nos permite enlazar las prácticas y las estrategias desplegadas por los agentes, así como también los elementos estructurales de los grupos sociales y de los individuos que son puestos en acción en un determinado contexto, entre ellos los capitales culturales, económicos y simbólicos (Tiramonti y Montes, 2008). Referirnos a las trayectorias educativas, nos posibilita alejarnos de los determinismos que podrían presuponerse acerca de las posiciones sociales de partida de los jóvenes, permitiéndonos observar espacios de quiebre y ruptura. Asimismo, los matices que introduce Terigi (2007) en torno a las trayectorias educativas nos permite incorporar a este concepto las heterogeneidades en los itinerarios de los estudiantes, reconociendo la existencia de distintas formas de experimentar un mismo tramo educativo. La autora distingue entre trayectorias educativas teóricas o ideales y las reales. Las primeras expresan itinerarios en el sistema que siguen la progresión lineal prevista por éste en los tiempos marcados por una periodización estándar; las segundas reconocen tanto itinerarios frecuentes o más probables, coincidentes con o próximos a las trayectorias teóricas; como recorridos que no siguen ese cauce, transitando su escolarización de modos heterogéneos, variables y contingentes.
Las trayectorias educativas son también condicionadas por la situación de vulnerabilidad social de las personas, aspecto que adquiere importancia a los fines de nuestra investigación. El concepto vulnerabilidad social remite a la inestabilidad de las instituciones públicas y políticas productoras de lazo social y a la exclusión en términos estructurales (Castel, 1997). Dentro de ese "aflojamiento" del lazo social Castel (1997) identifica una gama de posiciones intermedias entre la integración y la exclusión, que nos habilita a pensar en la exclusión como un proceso y en la vulnerabilidad como una zona con diversos grados de desafiliación y de carencia de recursos económicos, relacionales y de protección social, así como también la ausencia de protecciones y de inscripciones a instituciones dadoras de sentido. La vulnerabilidad social entonces puede ser entendida como la posibilidad de caer en situaciones de déficit que posicionan al sujeto en un lugar de pocas oportunidades, al reducirse su margen de acción.

A partir del desarrollo anterior, en el presente artículo se exponen los resultados obtenidos de uno de los objetivos de investigación, ${ }^{3}$ que consistía en identificar las razones aducidas por jóvenes en situación de vulnerabilidad social al inicio de sus trayectorias universitarias en instituciones públicas de gestión estatal. Asimismo buscamos ahondar en torno a aquellos factores que incidieron en la elección de estudiar en una institución universitaria determinada y no en otra. Consideramos que analizar las razones por las que ingresan estudiantes de sectores vulnerables a la universidad, así como también los aspectos que tienen en cuenta para decidir en qué universidad estudiar, constituye un aporte y contribución en pos de comprender y revertir la mencionada "inclusión excluyente", finalidad que excede a este trabajo.

Respecto de la estructura del artículo, en primer término damos a conocer aspectos metodológicos de la investigación. Luego desarrollamos dos secciones

\footnotetext{
${ }^{3}$ Este trabajo se desprende de mi tesis de maestría.
} 
principales. En la primera identificamos las razones aducidas por jóvenes en situación de vulnerabilidad social al inicio de sus trayectorias universitarias en instituciones públicas de gestión estatal, así como también los sentidos que atribuyen a esa trayectoria. En la segunda, nos referiremos a los factores que tuvieron en cuenta al momento de decidir en qué institución universitaria iniciar sus estudios, es decir, aquellos factores que incidieron en la elección de estudiar en una institución determinada y no en otra. Recalcamos que la separación entre las razones de por qué estudiar una carrera universitaria y en dónde estudiar, es una segmentación analítica y que, por lo general, ambos procesos de elección están imbricados, en este sentido los aspectos desarrollados en una sección pueden estar presentes al elegir en cuál universidad estudiar y viceversa. Por último introducimos algunas reflexiones que se desprenden de la investigación realizada.

\section{Material y método}

El universo de análisis del presente abordaje está comprendido por jóvenes de ambos sexos, en edad universitaria, residentes en el Gran Buenos Aires $(\mathrm{GBA})^{4}$ y que se encuentran en situación de vulnerabilidad social. Al recorte anterior se le agrega que se encuentran transitando el nivel de enseñanza superior universitario en alguna universidad de gestión pública y que formen parte del Programa Apuntalar Universidad $^{5}$ de apoyo a la trayectoria universitaria de jóvenes que cursan un conjunto determinado de carreras universitarias. ${ }^{6}$ Este Programa de inclusión universitaria se implementa desde 2008 y busca colaborar con la educación superior de jóvenes de 17 a 23 años en situación de vulnerabilidad social a través de una beca de estudio, ${ }^{7}$ y de tutorías universitarias. Su financiamiento proviene de una entidad bancaria local y es gestionado por organizaciones de la sociedad civil dedicadas a la inclusión educativa de jóvenes.

En este artículo se presentan parte de los resultados obtenidos en un estudio transversal, exploratorio y de metodología cualitativa, cuyo trabajo de campo fue realizado a lo largo del último trimestre de 2012. Las técnicas de investigación utilizadas fueron los grupos focales y las entrevistas en profundidad semiestructuradas. Para ambas técnicas se diseñaron guías de pautas ad hoc.

Se realizaron un total de seis grupos focales: dos de mujeres, dos de varones y dos grupos mixtos. Duraron cada uno de ellos una hora y media aproximadamente y el promedio de participantes por grupo fue de 7 personas, abarcando un total de 41 jóvenes. La selección de los participantes respondió a un muestreo dirigido o por conveniencia, siendo éste el que mejor correspondía a la búsqueda de perfiles particulares. De modo que la muestra no responde a criterios estadísticos, sino que busca recuperar la significatividad de determinadas características socioeconómicas, tales como lugar de residencia, trayectoria educativa de los becarios y de los padres, entre otras.

La cantidad de entrevistas individuales realizadas a becarios del Programa fueron 13: cinco de ellas se realizaron a residentes de Ciudad Autónoma de Buenos Aires (CABA) y ocho a residentes en el GBA. Su duración promedio fue de una hora y la media de edad de los entrevistados fue de 20 años. La selección de los entrevistados se realizó después de la participación de estos jóvenes en los grupos focales, seleccionando a

\footnotetext{
${ }^{4}$ El Gran Buenos Aires es definido por el Instituto Nacional de Estadísticas y Censos (INDEC) de Argentina como el área comprendida por la ciudad de Buenos Aires más los 24 Partidos del Gran Buenos Aires (INDEG, 2003).

${ }^{5}$ A los fines del presente trabajo y para mantener la confidencialidad del Programa así como también de sus integrantes, lo denominaremos con un nombre ficticio: "Apuntalar Universidad".

${ }^{6}$ Estas carreras son: Informática y todas sus derivadas, Administración de Empresas, Economía, Contador Público, Comercio Exterior y/o Ingeniería Industrial.

${ }^{7} \mathrm{Al}$ año 2012 el estipendio para los primeros dos años de estudio constaba de $\$ 850$ y para los cuatro años siguientes descendía a $\$ 650$. Esta diferencia se debe a que el Programa habilita a los becarios a trabajar a partir del segundo año de cursada.
} 
cada uno de ellos a partir de características que se revelaron en los esos grupos. Algunas de ellas fueron el clima educativo de sus familias, la distancia entre la universidad y su hogar, jóvenes con estudios universitarios previos aunque incompletos, su condición de migrantes de países limítrofes, estudiantes que en el nivel de educación secundario habían participado de tutorías y otros que no, entre otras.

Las dimensiones que abordaron las entrevistas y los grupos focales fueron: trayectoria educativa de los jóvenes, tanto en educación básica como universitaria; razones para decidir estudiar una carrera universitaria; razones para decidir en qué universidad estudiar; percepciones en torno a la universidad; aspectos de favorecen u obstaculizan sus trayectorias universitarias; relaciones con agentes de la institución universitaria, con agentes de las organizaciones de la sociedad civil que gestionan las becas y con sus pares; modos en los que se implementa el Programa y percepciones sobre su futuro. Este artículo presenta un recorrido por los hallazgos de dos de ellas: las razones vinculadas a optar por estudiar una carrera universitaria, y a la elección de en qué universidad estudiar. Para realizar este análisis utilizamos la teoría de la estructuración de Giddens (1995), entendiendo que las razones constituyen los principios fundamentales de la acción, de allí la posibilidad de racionalizar las acciones, siendo esta racionalización de la acción sobre la que se basa el concepto de acción intencional. Esto implica que los agentes tengan la capacidad de construir discursivamente su acción en el conocimiento de sí mismos y de los mundos sociales y materiales que conforman su ambiente. De allí que el análisis se realizará a partir del discurso de los estudiantes entrevistados ${ }^{8}$ en torno a las dimensiones abordadas en los grupos focales y entrevistas. Cabe resaltar que si bien las significaciones de una acción no se limitan solamente a aquellas que los agentes enuncian sino que también refiere a aspectos inconscientes (no dichos) de la motivación, a consecuencias no buscadas y al sistema de relaciones en el que éstas se inscriben; sí nos permiten acercarnos en gran medida a los significados de la acción en tanto la reflexión se realiza a partir de "marcos de significados" que organizan la vida social de los agentes.

\section{Resultados}

En la presente sección nos referiremos a los principales resultados obtenidos en la investigación respecto de las razones mencionadas a optar por estudiar una carrera universitaria y aquellas referidas a la decisión de en qué universidad estudiar. Vincularemos esas motivaciones con el contexto de vulnerabilidad social de los participantes del estudio, contexto que integra y juega su rol en la decisión de iniciar y continuar una carrera universitaria. Asimismo, en el desarrollo se propone analizar las operaciones subjetivas que los agentes ponen en acción en tanto posiciones estructuralmente similares, que pueden ser sostenidas y experimentadas de forma diferente (Ball, 2003). De modo que, además de lo estructural, es necesario incluir los aspectos subjetivos de la trayectoria educativa al intentar reconstruir las razones por las que los jóvenes decidieron dar los primeros pasos en la universidad.

\section{El inicio de la trayectoria universitaria: ¿para qué un título universitario?}

En este apartado nos referiremos a las razones aducidas por los entrevistados para iniciar y/o continuar su trayectoria educativa en la universidad. Antes de adentrarnos en la tarea propuesta, consideramos necesario aclarar que entendemos, junto con Veleda (2002), que los procesos de elección educativos y las razones aducidas a los mismos son hechos diacrónicos, complejos

\footnotetext{
${ }^{8} \mathrm{Si}$ bien un grupo focal no es sinónimo de una entrevista grupal en tanto en ésta última prima una comunicación unidireccional de cada participante con el coordinador (Merton, 1987 en Petracci, 2007), en este artículo nos referimoss también a los participantes de los grupos focales como "entrevistados".
} 
e incluso contradictorios, de allí la gran diversidad de aspectos que se encuentran vinculados a la selección de una alternativa. De modo que las dimensiones de análisis que incluiremos en el desarrollo siguiente, se combinan, conviven y coexisten en el proceso de elección educativa de los estudiantes.

\section{La gratuidad de las universidades públicas de gestión estatal}

En Argentina, el Estado nacional tiene como responsabilidad el financiamiento de la educación superior y, desde 1949, año en que se suprimieron los aranceles en las universidades, garantizar la gratuidad de los estudios de grado en las universidades públicas en todo el territorio nacional. Desde entonces la universidad de gestión estatal en Argentina ha forjado como característica identitaria la gratuidad (Carli, 2012).

Lo anterior se corrobora en las entrevistas realizadas en tanto observamos que la gratuidad de las instituciones universitarias aparece en las voces de los jóvenes como característica "dada", como una situación que no se problematiza. Entendemos que esta percepción compartida y libre de cuestionamientos constituye un factor subyacente al acceso de jóvenes en situación de vulnerabilidad social, erigiéndose como un elemento que, desde la visión de los entrevistados, hace posible que el ingreso a la universidad sea "para todo el mundo".

$\mathrm{Al}$ respecto, una de las participantes de los grupos focales refería a la gratuidad de la educación universitaria como el factor que hizo posible su ingreso a la universidad:

Yo siempre como que decía: "Quiero estudiar, quiero estudiar", desde chica. Pero después te vas dando cuenta que te tenés que acomodar a las posibilidades que tenés, quería estudiar pero también tenía la necesidad de trabajar. Mis papás me ayudaban con lo que podían, que no era mucho, pero bueno, me ayudaban. Una privada era imposible, una del Estado sí, pero tenía que ver cuál (Grupo Focal 5).

En el trabajo de campo identificamos algunos estudiantes que en su instancia de decisión contemplaron la posibilidad de estudiar en una universidad privada (sobre todo aquellos que residen en la Ciudad Autónoma de Buenos Aires donde la oferta de universidades de gestión privada es mayor). Pero estudiar en estas universidades, tal como se lee en el fragmento anterior, fue descartada por la elevada proporción del ingreso de sus hogares que representaría su cuota, porque estaba "fuera de su alcance".

Otra de las razones referidas por los entrevistados para no estudiar en una universidad privada es, tal como observamos entre los pocos a los que se les presentó la posibilidad de estudiar en una de ellas - beca de estudios mediante-, la calidad educativa y/o el prestigio de la institución atribuida a las universidades de gestión estatal. Tal como veremos algunas líneas más adelante, el prestigio ha sido identificado como una de las características de las instituciones que los estudiantes tienen en cuenta para decidir estudiar en una universidad y no en otra.

Observamos incluso que la gratuidad en el sistema de educación superior se erigió con más fuerza por sobre la gratuidad de la educación media, en tanto algunos de los estudiantes entrevistados sí concurrieron a colegios secundarios privados: ${ }^{9}$

\footnotetext{
Es privada [la Universidad de Morón] y mi mamá me dijo: "Yo una privada no te voy a pagar" porque me dijo para ella el colegio fue muy importante, fue lo que pudo cubrir pero que ya la universidad no iba a poder. Sí me iba a poder ayudar los primeros años, pero ya pagar una cuota no (Grupo Focal 3).
}

\footnotetext{
${ }^{9} \mathrm{El} 41 \%$ de los estudiantes que participaron de la investigación concurrió a una escuela de enseñanza media de gestión estatal, un $5 \%$ de gestión privada laica y un 54\% en colegios privados religiosos. Este último porcentaje se encuentra explicado principalmente por la alta proporción de estudiantes a los que les gestiona su beca una organización de la sociedad civil perteneciente a una congregación católica y que trabaja con egresados de colegios pertenecientes a la misma.
} 
A partir de lo anterior, inferimos que la gratuidad parece ser el "piso mínimo", la base sobre la cuál construyen las reflexiones en torno a su trayectoria universitaria. Se desprende entonces de los discursos relevados que la posibilidad de acceder a la universidad de forma gratuita constituye un rasgo del contexto social de la experiencia de los jóvenes, un marco de referencia, el cimiento fundamental desde el cual les es posible proyectar su trayectoria universitaria.

Cabe resaltar que más allá de que la gratuidad sea un factor fundamental que posibilita su ingreso a la universidad pública, en los discursos de los jóvenes se hace referencia también a los gastos en los que deben incurrir para estudiar una carrera universitaria, entre ellos refirieron a la compra de los apuntes, los costos del transporte, su alimentación en los ratos que pasan fuera de su casa. Al respecto, algunos estudiantes indicaron que para poder cubrir esos gastos relacionados con su estudio universitario, las estrategias familiares de vida (Torrado, 1981 y 2003) se vieron modificadas. Así, algunos de los estudiantes pensaron en salir a trabajar para generar un ingreso que les permitiera poder estudiar una carrera universitaria - es plausible pensar que el efectivo despliegue de esta estrategia podría haberse modificado al recibir una beca de estudio por parte del Programa Apuntalar Universidad - o bien alguno de los adultos de la familia tuvo que modificar su situación laboral, ya sea pasando de ser inactivo a activo o bien incurriendo en una mayor cantidad de horas trabajadas.

\section{Las experiencias y expectativas familiares}

Los relatos de los jóvenes indican también como uno de los factores que incidieron en su ingreso a la universidad las expectativas de su familia, ${ }^{10}$ expectativas que en muchos casos fueron interiorizadas y apropiadas por los estudiantes hasta integrar su subjetividad y por lo tanto de los sentidos autoatribuidos a su trayectoria.

Como una primera forma de sumergirnos en la trama que relaciona elecciones individuales educativas e intereses de las familias en torno a ellas, nos pareció interesante para contextualizar la toma de esas decisiones conocer el nivel educativo de los hogares. Si bien estrictamente el clima educativo del hogar es el indicador que registra el promedio de años de estudio alcanzados por el conjunto de las personas de 25 y más años que residen en el hogar (Bustos et al., 2001), construimos un indicador que da cuenta del nivel educativo agregado de los adultos mayores del hogar, aproximándonos al "clima educativo" del hogar. El clima educativo "bajo" corresponde a aquellos hogares en los que el mayor nivel educativo de los adultos responsables se encontraba entre primario completo-incompleto $(15 \%)$ y secundario incompleto (29\%); "medio" para los que el mayor nivel educativo de los adultos responsables fuera secundario completo $(34 \%)$ y por último "alto" para los hogares en que algunos de los adultos contaba con "terciario-universitario incompleto" (12\%) o bien "terciario-universitario completo" (7\%). En suma: el 44\% de los entrevistados pertenecía a hogares con un nivel educativo bajo, un 34\% medio y el $19 \%$ restante alto. Esto nos permitió contextualizar la trayectoria educativa de los jóvenes en tanto nos aproximó al clima educativo de sus familias.

Antes de profundizar el análisis de esta dimensión, cabe destacar que consideramos que no necesariamente todos los miembros de la familia actúan de la misma forma y/o comparten una misma racionalidad, sino que pueden convivir, dentro de la misma unidad familiar, diversas miradas, formas de relación, funciones o roles. En este sentido, siguiendo a Lahire (1997, en Tiramonti y Ziegler, 2008) se torna

\footnotetext{
${ }^{10}$ Entendemos a las familias como personas en relación que se vinculan por lazos de parentesco. Si adicionamos la referencia a los "hogares", estas personas conviven bajo un mismo techo (Montes, 2004).
} 
analíticamente riesgoso presentar como homogéneos a sectores o grupos que poseen un repertorio múltiple de estrategias distintas e incluso opuestas en algunos casos. Es decir, en nuestro caso situaciones de vulnerabilidad equivalentes o bien un similar clima educativo en el hogar, no conlleva necesariamente a trayectorias educativas iguales, sino que la experiencia de cada sujeto, sus interacciones con diversos actores, los sentidos atribuidos, entre otros, implican recorridos diferenciados.

A partir de las entrevistas identificamos una fuerte vinculación entre las decisiones individuales de los estudiantes y las trayectorias familiares, o bien de algunos de los miembros de la familia. Al respecto identificamos un grupo mayoritario de los jóvenes entrevistados que refiere a un incentivo por parte de sus familias en el inicio y continuidad de su trayectoria en la universidad. De modo que el grupo familiar en el que se encuentran insertos, aun cuando ninguno de sus miembros haya pisado esas instituciones, alienta su inserción educativa. Esta incidencia positiva puede ser leída en los siguientes fragmentos:

Entrevistadora: Y en cuanto a personas que te pudieron ayudar, amigos...

Entrevistada: Con mi mamá, a pesar que es humilde y está donde estamos, siempre me incentivó a estudiar. Claro, de una familia humilde, el anhelo es que al menos alguien pueda formarse y ser alguien, así que siempre [me apoyó] (Entrevistada 7).

Hasta mi abuelo de 90 años, buscaba apoyarme y decir: "Mira, para ser alguien, para crecer, formal, profesional, personalmente, tenés que ir a una universidad y salir del colegio y romper esa burbuja" (Grupo Focal 3).

Vinculado a lo anterior, en algunos de los testimonios de los jóvenes entrevistados surge la explícita referencia a las expectativas que algunos de sus familiares depositan en ellos, en tanto perciben que los jóvenes cuentan con mayores posibilidades respecto de las que en su momento tuvieron los miembros ahora adultos de sus familias. Los entrevistados, al reflexionar sobre su propia trayectoria, no pudieron dejar de lado este aspecto contemplando como una de las razones del inicio de su carrera también los deseos y prenociones de sus familias.

Por otro lado encontramos también un grupo minoritario de entrevistados entre quienes el incentivo por parte de sus familias para estudiar una carrera universitaria no tenía lugar, ya sea porque sus familiares mantenían una posición más bien neutra, vinculada principalmente a un desconocimiento sobre las instituciones y sus dinámicas, o bien directamente porque no estaban de acuerdo con que ingresaran a la universidad. Respecto de estos últimos, pareciera que las expectativas de sus familias no fueran coincidentes con lo que desean los jóvenes para su propia vida, en tanto se observó que algunos de los adultos mayores de sus familias parecían tener otras ideas de qué harían sus hijos o bien consideraban estudiar como una "pérdida de tiempo". Observamos que en algunos casos esa contradicción con su grupo familiar, o con parte del mismo, pasa a integrar las razones y/o motivaciones para estudiar, intentando diferenciarse de las experiencias de sus familiares. $\mathrm{Al}$ respecto incluimos un caso emblemático de esta situación:

Entrevistado: Mi papá no tenía en la cabeza que estudiemos. Es más, cuando ingresé a la Facultad me dijo: “¿Vos querés ingresar en la Facultad? ¡Vas a trabajar!! [con tono de reto]". Y en el colegio, él [...] me acuerdo que una vez me dijo [...] porque yo a la vez de ir al colegio también lo ayudaba a mi viejo. El tiempo que tenía lo ayudaba a mi viejo, iba al colegio y después iba a donde él trabajaba. Un día él nos dijo a mi hermano mayor y a mi: “¿Qué van a hacer? ¿Estudiar o trabajar?”

Entrevistadora: O sea que les dio la opción de "estudiar"...

Entrevistado: Sí, pero yo sentía más que nos empujaba a trabajar. Yo quería estudiar [...] pero 
terminé diciendo estudiar y trabajar. Y así fue, siempre laburé $[. .$.$] todo mi paso en el colegio [secunda-$ rio] lo ayudé (Entrevistado 11).

Es posible suponer que la discrepancia observada entre los deseos de los jóvenes y los de sus familias respecto del inicio de su trayectoria universitaria, podría estar vinculado a que la situación socioeconómica de estas familias y sus estrategias familiares de vida (Torrado, 1981 y 2003) se encontraban por lo general más vinculadas a la preocupación por la supervivencia, no así a la posibilidad y/o expectativas por que sus hijos logren una mayor cantidad de años de educación.

\section{Expectativas de movilidad social ascendente: "ser alguien"}

Tal como comentamos antes, el incremento de la matrícula universitaria refiere tanto a procesos que tuvieron lugar dentro del sistema educativo, entre ellos procesos de inclusión educativa de sectores que antes se encontraban relegados de la educación superior universitaria, una mayor cobertura lograda por el nivel de enseñanza medio y el aumento de la cantidad de instituciones universitarias; como a continuidades en las valoraciones y expectativas de movilidad social ascendente de la sociedad argentina en torno a la educación, aspecto que se encuentra muy enraizado en la trama sociocultural de nuestro país.

Las elecciones en materia educativa forman parte de estrategias de adquisición de capitales sociales, económicos y culturales legítimos. Específicamente nos referimos al capital cultural, las expectativas y las pretensiones de ascenso y movilidad social ascendente, que se estructuraron en torno a la adquisición del mismo (Carli, 2012; Dussel, 2005; Mayer, 2012; Tiramonti y Montes, 2008; Tiramonti y Ziegler, 2008).

Estos deseos de movilidad social ascendente a partir de obtener un título universitario, emergieron en las entrevistas realizadas como una de las razones enunciadas para el inicio de su trayectoria en la universidad. Su elección educativa actual se vincula con el deseo de "ser alguien", de percibir al título universitario como aquello que los llevará a ascender socialmente.

En estos jóvenes que, tal como describiéramos anteriormente, se encuentran en situación de vulnerabilidad social, la educación se erige como la principal vía de ascenso social ("posibilidad de progreso"), situación que les permitiría "salir" de situaciones de la vulnerabilidad y de inseguridad social. En palabras de una entrevistada:

Entrevistadora: ¿Qué pensabas en relación a estudiar una carrera universitaria?

Entrevistada: Para mí era la posibilidad de progreso, yo pensaba que sin estudios uno no podía lograr nada en la vida, porque se iba a quedar siempre en un trabajo mediocre en un trabajo que no le gustara, en cambio si es algo que a uno le gustara podía hacerlo por el resto de su vida y ser feliz y poder progresar cada vez más (Entrevistada 5).

Se desprende del discurso de los entrevistados que estudiar en la universidad y por lo tanto una mayor cantidad de años de estudio, es aquello que les dará la posibilidad de contar con un trabajo en mejores condiciones del que hubieran obtenido si no hubieran estudiado en la universidad, que les permitirá apartarse de la precarización laboral, que les garantice el acceso a lo "material". El título universitario funciona, según el sentido que le atribuyen los entrevistados, como una especie de "respaldo", una "garantía" para conseguir un trabajo, que incluso les guste, en el futuro.

Para pensar la vinculación entre los años de estudio y las posibilidades de inserción en el mercado de trabajo, sostendremos que aun en un mercado laboral segmentado y el consecuente incremento de las desigualdades sociales que se encuentra fuertemente relacionada al estrato social de pertenencia (Jacinto, 2008), continúa siendo posible afirmar que una 
mayor cantidad de años de escolarización brindan una mayor protección laboral y mejores ingresos (Gallart, 2000; Kritz, 2005, en Jacinto, 2008).

Las expectativas de ascenso social comunes a muchos de los jóvenes entrevistados permanecen en sus discursos y nociones compartidas, aun cuando las posibilidades concretas de movilidad social ascendente vinculada a mejorar las trayectorias ocupacionales se hayan ido desdibujando y perdiendo vigencia; los movimientos de ascenso y descenso se repartan casi aleatoriamente; y cuando las reconfiguraciones en el peso relativo de los factores que inciden en los procesos de movilidad social parecen haber cambiado. Entre éstos últimos observamos modificaciones en las contribuciones de la educación en la obtención de mejores empleos (Kessler y Espinoza, 2003). Estas situaciones donde se corrobora una diferencia entre movilidad social real y la percepción subjetiva de movilidad son denominadas por Kessler y Espinoza (2003) como "movilidad espuria", que implica que si bien hay sectores sociales que ascienden socialmente, la significación y características de estos movimientos no son idénticas al pasado en tanto las recompensas asociadas a los puestos alcanzados son menores que antaño.

A modo de cierre del presente apartado podríamos afirmar que se observaron matices en el deseo de movilidad social ascendente. Así, quienes se encuentran inmersos en una situación de menor vulnerabilidad social, refieren que el título universitario les aportará posibilidades de "progresar", de "estar mejor". Por su parte, entre aquellos jóvenes que presentan una mayor vulnerabilidad social pareciera encontrase más extendida la noción de que con el título pasarían a "ser alguien". Se desprende de lo anterior que sería a partir de la obtención de esta credencial educativa que podrían construir su identidad, construcción que prioriza por sobre todos los otros aspectos los profesionales, en tanto pasarían a "ser alguien" sí y sólo sí estudian. Cabe preguntarse si esta relación se encuentra vinculada a una noción de meritocracia más extendida entre estos jóvenes en particular y que se encuentra reforzada por las mismas instituciones educativas.

\section{Deseos de emancipación}

Vinculado a algunos de los aspectos trabajados en el apartado anterior, surge del discurso de los jóvenes entrevistados como otra de las razones que los llevaron a acceder a la educación superior universitaria el deseo de emanciparse, o al menos imbuirse en prácticas emancipadoras que los inician en ese deseo. Este anhelo que se plasmaría obteniendo el título universitario, y por lo tanto en el largo plazo, por lo general se encuentra vinculado a la concreción de la independencia económica de sus familias y a contar con una estabilidad económica. Justamente, y tal como se desprende del fragmento incluido a continuación, la universidad aparece como una vía para lograrlo:

Creo que teniendo un título y pudiendo trabajar podría lograr una independencia económica de mis padres, voy a poder arrancar una vida, no sé si solitaria es la palabra, pero de independencia seguro que sí. No le voy a tener que pedir más nada a mis viejos. Me voy a bancar yo solo (Entrevistado 8).

Si bien en la mayoría de los casos este deseo emancipador emerge vinculado a lo económico, no se vincula solamente a ello. Una minoría, sobre todo aquellos que se encuentran en un mayor grado de vulnerabilidad social, refieren también a un deseo emancipatorio con arraigos en lo habitacional y en lo vincular.

Respecto de la emancipación en torno a lo habitacional, varios de los jóvenes manifestaron vivir en algunas de las formas que adquiere en los sectores sociales más bajos la segregación urbana: los asentamientos o villas miseria. Otros entrevistados refirieron a sus barrios como "precarios" o "humildes". Residir en estos emplazamientos implica la percepción de 
estar expuestos a diversas inseguridades, o bien con una oferta restringida de medios de transporte. El GBA es una megaciudad en términos de Borja y Castells (2000), que viene experimentando y experimenta procesos de fragmentación, es decir, que atraviesa en términos de Quintin (1997, en Ziccardi, 2001) un proceso de profundización de las formas territoriales de la exclusión y un deterioro del habitat popular. Al respecto, las villas miseria y los barrios "humildes" son formas de residencia que constituyen "soluciones" habitacionales que forman parte de las transformaciones socioespaciales que atraviesan las grandes ciudades en Argentina y constituyen procesos "socioterritoriales" ligados a cambios económicos, culturales y sociales más amplios (Torres, 1998).

Habitar en esos fragmentos excluidos ha sido posiblemente una situación que implicó que algunos de los entrevistados identificaran a la educación universitaria como una forma de salirse de esos emplazamientos geográficos, salir del barrio en el que viven, separarse de él y de algunas de las situaciones que en éste tienen lugar. Esta opción de emancipación parece más cercana a partir de las posibilidades que ellos consideran que ofrece la universidad.

Yo vivo en un barrio que es feo, es chiquito, es una villa, te quedás sin luz, sin agua, no es una villa común, es bastante feo, tiene bastantes cosas, hay inseguridad, de todo [...] es como que basta! Yo no quiero quedarme acá, morirme acá. Entonces me pregunto, bueno: “¿Qué tengo que hacer para irme de acá?” (Grupo Focal 5).

Por otra parte, la emancipación refiere también al deseo de emanciparse desde lo vincular, dejar de lado ciertos códigos relacionales que los jóvenes no comparten. Por momentos incluso, su barrio es visto como un lugar de excesos, que se sitúa en los bordes de los problemas sociales, que podrían ser evadidos si lograran salir del barrio. En este sentido, la posibilidad de distinguirse de las facciones de las cuales son originarios (Bourdieu, 1988) aparece como una posibilidad de diferenciarse y de hacer cosas nuevas.

Otro de los aspectos que parece diferenciarlos de algunos de sus antiguos compañeros de colegio secundario o bien amigos de esos tiempos, es que los entrevistados han optado por posponer su maternidad-paternidad, priorizando su trayectoria universitaria.

Cabe aclarar que este proceso de emancipación referido a lo vincular, si bien parece cobrar más fuerza entre quienes se encuentran en mayor grado de vulnerabilidad social, no se extiende a todos los estudiantes entrevistados. $\mathrm{Al}$ respecto varios nos comentaron que mantienen el vínculo con sus "amigos de siempre" y continúan compartiendo sus ratos libres con ellos.

Si bien a los fines del presente análisis hemos optado por desglosar los diversos tipos de emancipación identificados -emancipación económica, geográfica y vincular-, esta decisión es analítica y no implica que estos deseos emancipadores no sean plausibles de darse en conjunto, en tanto desear uno no implica una imposibilidad de ansiar el resto.

\section{Red de relaciones}

Y sé que todo eso me va a dar la Facultad. Me va a abrir las puertas de un mundo, que no conozco, que no viví, que solamente lo veo por la gente que en estos últimos tiempos me estoy comenzando a relacionar. Es como la puerta de entrada (Entrevistado 11).

De este modo uno de los entrevistados enuncia las posibilidades vinculadas al plano relacional como otro de los aspectos que conlleva su transitar en la universidad, oportunidades que trasvasan lo material y/o a los saberes a incorporar. La construcción de relaciones novedosas nos remonta necesariamente a la acumulación de capital social legitimado como una de las razones, aunque vinculado a un plano inconsciente, del inicio de la trayectoria universitaria de algunos de los jóvenes entrevistados. 
El capital social refiere al agregado de recursos reales o potenciales asociados a la posesión de una red de relaciones duraderas que un agente puede movilizar en un determinado momento (Bourdieu, 1985). Éste, al igual que los capitales económicos, culturales y simbólicos, requiere de esfuerzos por parte de los agentes para aumentar o disminuir su volumen.

La mención a la universidad como una "puerta de entrada" implica esa intención de acercarse a un mundo desconocido, donde tienen lugar relaciones que intrigan, pero que al mismo tiempo exigen un esfuerzo por parte de los agentes que allí se inserten. Tejer esas novedosas redes puede permitirles también, ya sea consciente o inconscientemente, obtener un mayor rendimiento del resto de los capitales que los jóvenes objeto del presente estudio poseen en menor volumen.

La construcción de estas redes implica la constitución de espacios de articulación que los dotan de un respaldo, un sostén, un apoyo que contribuye a su trayectoria educativa.

La noción de capital social emerge no sólo en lo que refiere a las relaciones que pueden construir en la universidad, sino también en torno a las posibilidades laborales con las que contarán luego de haber ido a la misma. Siguiendo a Jacinto (1997 y 2008), si bien el contexto de segmentación laboral, con indicadores de informalidad y precarización altos, condiciona a los jóvenes en general y en particular a los que pertenecen a sectores sociales más bajos, éste no determina la trayectoria de los jóvenes, sino que ellos pueden contribuir en la gestión de su inserción en el mercado de trabajo, de allí que el incremento del capital social también es un elemento que favorece el acceso a mejores empleos. En este sentido una de las participantes de los grupos focales mencionaba:

La vida social que uno tiene, por ejemplo no es lo mismo terminar el colegio y trabajar en una fábrica que estudiar y trabajar de algo que te gusta, estar mejor económicamente, socialmente. Por una cuestión de capacidad digamos, en lo laboral, estudiar te abre una puerta gigante a buscar un buen trabajo (Grupo Focal 1).

Observamos que a menudo la construcción de estas "nuevas redes sociales" puede verse impulsada también por el deseo de diferenciarse de sus anteriores relaciones, situación que anteriormente referíamos como emancipación vincular.

\section{La elección de la universidad: ¿dónde estudio?}

Anteriormente dimos cuenta de las diversas razones enunciadas por los jóvenes vinculadas a la decisión inicial de estudiar una carrera universitaria. Pero, a la decisión de porqué estudiar una carrera universitaria, en nuestro análisis nos interesaba también conocer el recorrido realizado en torno a la pregunta: ¿en qué universidad estudio? ${ }^{11}$

A partir del discurso de los jóvenes entrevistados, nos fue posible identificar que las principales dimensiones que tienen en cuenta al momento de elegir dónde estudiar corresponden a la proximidad geográfica y al prestigio atribuido a la institución. Estos aspectos pueden haber sido tenidos en cuenta, tanto para afirmar una elección, como para aseverar una "no elección". Destacamos que no todos los jóvenes entrevistados ponderan de la misma forma estas dimensiones, sino que justamente de allí se observa la diversidad y mixtura de las distintas trayectorias de los jóvenes.

\section{La proximidad geográfica}

$\mathrm{Al}$ indagar por los aspectos que tuvieron en cuenta al elegir en qué universidad estudiar, uno de ellos refiere a la distancia existente entre las instituciones

\footnotetext{
${ }^{11}$ La decisión en torno a qué carrera estudiar integra también el proceso de toma de decisión, pero dado que sólo son plausibles de ser incluidos en el Programa Apuntalar Universidad quienes estudian determinadas carreras (Informática y todas sus derivadas, Administración de Empresas, Economía, Contador Público, Comercio Exterior y/o Ingeniería Industrial), no abordaremos ese aspecto.
} 
y sus hogares. Este aspecto toma más fuerza sobre todo entre aquellos jóvenes que residen en alguno de los 24 partidos del Gran Buenos Aires. Entre ellos, el $46 \%$ concurre a una institución universitaria ubicada en la Ciudad Autónoma de Buenos Aires.

La referencia al tiempo que insume el traslado, a las peripecias del transporte público ("pasaron $7 \mathrm{Co}^{-}$ lectivos y ninguno paró", "tomar el tren la verdad y todo eso, incendios de por medio... se hace "heavy"), la disminución de las horas de sueño, entre otros, dan cuenta de las implicaciones e importancia que la proximidad o bien la lejanía de las universidades tiene sobre la decisión de dónde estudiar. Incluso, algunos de los jóvenes que residen en el GBA pero que estudian en CABA expresaron su enojo y se refirieron al cansancio que el traslado les provoca, llegando a incidir en su trayectoria educativa.

Mencionábamos en la introducción del artículo que la ampliación de la oferta educativa ha sido otro de los fenómenos que alentaron la masificación de la educación superior universitaria. Esta expansión, explicada en términos de Chiroleu y Marquina (2012) por tres "olas de fundación", ha conllevado a que se emplazaran universidades en diversas áreas de nuestro país, entre ellas varias localidades del Gran Buenos Aires.

La creación de universidades en lugares "atípicos" plantea diversas consecuencias tanto a nivel social, ya que tiene su impacto en los emplazamientos geográficos en los que se fundan las universidades, como a nivel sociológico, al incorporar una mayor proporción de estudiantes cuyos padres poseen menores ingresos y/o menores niveles de instrucción que quienes ingresan a las universidades tradicionales, y a nivel económico, por su aporte científico y tecnológico (Pochulu, 2004).

Refiriéndonos específicamente a los impactos a nivel geográfico, la apertura de universidades en lugares atípicos conlleva la ampliación de las oportunidades de acceso al nivel de enseñanza universitario, al vencer una posible barrera de acceso o bien un factor que influye en la continuidad de una carrera: la distancia existente entre las instituciones y los hogares de los estudiantes. Parece que para algunos de los entrevistados la cercanía geográfica aproxima a la institución y la erige como algo "posible". En palabras de uno de los entrevistados:

Yo terminé el secundario y me puse a estudiar el CBC [Ciclo Básico Común de la UBA] para medicina y después dejé. Al mismo tiempo estaba trabajando y me estaba pagando yo los gastos. Después estuve [trabajando] en La Rural, después laburaba en un mayorista y después de tres años volví a estudiar. Ahora estoy en primer año y bueno ya [...] $\mathrm{Al}$ mismo tiempo que estaba en el CBC estaba trabajando en Mc Donalds. Estudiaba en Avellaneda, trabajaba en Quilmes y vivía en Varela y todos los días salía a las 5 de la mañana. Ahora estoy estudiando en Varela, en la UNAJ [Universidad Nacional Arturo Jauretche], abrió hace dos años esa facultad y es medio arriesgado porque no hay ninguna... y al final dije: "Está cerca, es una posibilidad" (Grupo Focal 2).

Cabe retomar la acepción de Pérez Rasetti (2012), quien para referirse a la expansión y extensión de las instituciones universitarias hasta aproximarse geográficamente a los jóvenes, hace uso del término "vecinalización". Las nuevas instituciones constituyen "ofertas de proximidad", como las denomina el autor, que hacen posible la inclusión de chicos y chicas que de otro modo no hubieran ingresado a la universidad. Entendemos la proximidad no sólo geográficamente, sino también como una aproximación de las instituciones a los jóvenes. De allí que logren constituirse en una opción posible.

Cabe resaltar que para algunos de los jóvenes entrevistados estudiar en estas "ofertas de proximidad" no constituyó su primera opción, sino que por una sensación de mayor prestigio o bien porque no integraban su imaginario respecto de "la universidad", 
se inscribieron primero en universidades más tradicionales. Pero los largos trayectos, el "tiempo perdido", la "mayor tranquilidad", entre otros factores, incidieron en que finalmente se decidieran por estas "nuevas universidades".

La proximidad geográfica, aun entre aquellos entrevistados que eligieron universidades más tradicionales incluso cuando implicara tener que trasladarse, es una dimensión que tienen en cuenta al relatar su trayectoria educativa. Al respecto, la importancia de esta dimensión puede ser observada en el caso de este participante de los grupos focales quien, aún viviendo en la zona oeste del Gran Buenos Aires y siendo consciente de las complicaciones que acarrea el traslado, elige cursar en la Universidad de Buenos Aires (UBA):

Yo veía más la posibilidad, del inconveniente en lo que era el viaje. Yo vivo en Merlo, y en Merlo te tenés que tomar un tren hasta estación Once y después recién ahí moverte. Después había un CBC en Merlo, lo cerraron, entonces tuve que ir al CBC que está en Paternal, ahí media hora hasta Liniers y después media hora en el colectivo [...] Entonces ése era el problema por el cuál la UBA era un inconveniente, más para mi papá que para mí o mi mamá, porque yo hablaba con ellos. Yo quería la UBA por el prestigio y porque no hay que pagar la universidad. Y mi papá por ahí me decía: "Andá a la Universidad de Morón, no importa, la pagamos igual, es más cerca". Empecinado, yo: "Vamos a la UBA, pero bueno, lo que más se complica es eso, el viaje" (Grupo Focal 4).

Corroboramos que la importancia atribuida a la cercanía y/o lejanía de la institución es heterogénea. Así, para algunos es un aspecto estructural más a tener en cuenta, es decir si bien la distancia es vivenciada y forma parte del relato de los jóvenes, ésta no constituye un obstáculo para sostener la elección de la institución en la que transcurre su carrera universitaria. Otros, en cambio, le otorgan gran importancia a la cercanía y/o lejanía de la universidad, situación que pareciera repercutir de dos formas en las trayectorias universitarias de los jóvenes. Una de ellas implicaría que la distancia a la que se encuentra ubicada la institución respecto de sus hogares condiciona en gran medida la respuesta a la pregunta ¿'en qué universidad estudio?, en tanto priorizan las instituciones que se encuentran más cerca de sus casas para reducir el tiempo y los gastos de viaje. La segunda consecuencia, si bien la distancia de la universidad es grande, e incluso hay momentos en que incide en la trayectoria universitaria de los jóvenes (los irrita, genera que falten, disminuye las posibilidades de juntarse a estudiar en grupo, entre otros), no implica que elijan otra institución para continuar sus estudios. De ésto se desprende que existirían otros factores que hacen que los estudiantes mantengan su decisión más allá de la distancia. Muchos de ellos tendrán que ver con los aspectos antes mencionados sobre el para qué estudiar, pero también hay otros aspectos en los que basan su elección por una institución y no por otra.

\section{El prestigio atribuido a la institución}

$\mathrm{Al}$ indagar en torno a las razones por los que eligieron estudiar en una universidad y no en otra, emerge la noción de "prestigio". Entendemos que éste constituye una atribución de sentido en términos weberianos (Weber, 1965) y por lo tanto compartida y construida intersubjetivamente. Estas atribuciones de sentido integrarían los "marcos de significado" desde los que los agentes interpretan las acciones, los sucesos y la propia conducta, así como también organizan su vida social práctica (Giddens, 1987).

El prestigio apareció entre los jóvenes como una categoría compartida por muchos de ellos y utilizada para interpretar a las instituciones universitarias, dotarlas de sentido y clasificarlas. En su relato la construcción del elemento prestigio en torno a las instituciones universitarias, se erigió como característica 
y elemento de distinción entre unas y otras, posibilitando la clasificación de las casas de estudio según posean en mayor o menor medida ese atributo. El "prestigio" se presenta en el discurso de los jóvenes como un rasgo positivo. Por lo general se lo vincula a la Universidad de Buenos Aires, que aparece en sus discursos como sinónimo de excelencia, como portadora de un estatus compartido, apreciación que se resume en la frase: "La UBA es la UBA".

La construcción del prestigio en torno a las instituciones apareció no solamente trasvasando lo vinculado a la calidad educativa, sino que también relacionado a las mayores posibilidades laborales que otorgarían. Esto es de gran importancia, en tanto tal como referimos anteriormente, constituyen dimensiones que integran las motivaciones que los jóvenes resaltan al momento de fundamentar el porqué del inicio y continuidad de su trayectoria universitaria:

Obvio que si estudiaste en una universidad de poco prestigio, poco renombre que no conoce mucha gente, tal vez tengas dificultades a la hora de conseguir ese empleo, pero yo creo particularmente que cuando en un trabajo vos les decís que sos de la UBA te miran ya de otra forma, aparte las preguntas en una entrevista lo notan, se nota (Grupo Focal 4).

Observamos a partir del relato de algunos de los jóvenes entrevistados que la construcción que poseen en torno a la noción de prestigio pareciera permitirles ubicar en una escala a las instituciones. Así como la UBA se encuentra en la posición más alta de esa escala, es también ese "sistema de clasificación" el que les permite interpretar y catalogar al resto de las instituciones. De modo que el prestigio aparece como una construcción colectiva a partir de la cuál comparan las instituciones, ya sean de gestión pública o privada.

Esta forma de clasificar las universidades, se la atribuyen también a otros que replicarían esa valoración de los títulos al momento de seleccionar una persona para cubrir un puesto de trabajo, construyendo así cierto "mito" en torno a la selección de personal:

No, yo quería pública antes que privada. La plata sí influye, pero no solamente por eso, sino porque tiene más respeto, a mí siempre me contaron que agarran un currículum de la UBA y agarran uno [de la Universidad] de Morón o de la UADE [Universidad Argentina de la Empresa] que son privadas y levantan más el de la UBA por más que el promedio sea cuatro. Siempre me contaron eso, no sé (Grupo Focal 4).

$\mathrm{Al}$ analizar las opciones de universidades según el clima educativo del hogar se observa que aquellos jóvenes que provienen de hogares con clima educativo "bajo" ( $45 \%$ de los entrevistados) son entre quienes se corrobora una mayor amplitud en las casas de estudio seleccionadas; mientras que entre los que provienen de hogares con clima educativo "alto" (20\%) corresponden a los que concurren en mayor medida a la UBA. A partir de ello es plausible considerar que la reputación de las universidades tradicionales pareciera reproducirse en los grupos de mayor clima educativo, mientras que los hogares de clima "medio" y "bajo" parecen ser más permeables a las "nuevas" opciones. O bien al revés, estas universidades "vecinas" se presentan como más próximas a éstos jóvenes. Lo que no implica que la noción de prestigio de las instituciones como un aspecto a valorar no se encuentre extendida en todos los hogares, independientemente de su clima educativo.

\section{Reflexiones finales}

Si bien las trayectorias educativas de los jóvenes no se encuentran determinadas por los elementos estructurales, sí inciden en ellas y se encuentran presentes elementos de esa índole entre los que cabe mencionar los capitales culturales, simbólicos, sociales y económicos (Tiramonti y Ziegler, 2008). 
Partiendo de la premisa anterior, en el presente artículo, buscamos identificar las razones aducidas por jóvenes en situación de vulnerabilidad social al inicio de sus trayectorias universitarias en instituciones públicas de gestión estatal. Asimismo buscamos ahondar en torno a los factores que incidieron en la elección de estudiar en una institución universitaria determinada y no en otra. Todas estas razones identificadas se combinan, conviven y coexisten en el proceso de elección educativa de los estudiantes.

Una de las razones aducidas al inicio de su trayectoria fue la gratuidad de las instituciones universitarias públicas de gestión estatal. Este rasgo constituye un factor subyacente que hizo posible y favoreció la inserción de jóvenes en situación de vulnerabilidad social. La gratuidad pareció ser el "piso mínimo", la base que les permitió iniciar su trayectoria universitaria, el cimiento fundamental desde donde pudieron proyectar su trayectoria universitaria. Cabe referir que este aspecto de las universidades públicas de gestión estatal ha sido entendido como una característica dada de las mismas, dando cuenta de ello su poca problematización. Más allá de ellos, la valoración de la gratuidad como algo fundamental, no generó que perdieran de vista la necesidad de incurrir en otro tipo de gastos necesarios para su trayectoria universitaria (compra de apuntes, gastos de transporte y alimentación, etcétera).

Los relatos de los jóvenes narraron también como razones de importancia, ya sea como incentivo o bien como dificultad para sumergirse en la universidad, las expectativas de sus familias en torno a los estudios universitarios. Observamos que con frecuencia ellos mismos interiorizaron estas expectativas familiares pasando a formar parte de su propia subjetividad. En su mayoría los jóvenes entrevistados refirieron que sus familias los incentivaron en el inicio y continuidad de su trayectoria en la universidad, alentando su inserción educativa. Por su parte encontramos un grupo minoritario de entrevistados que refirieron que su grupo familiar mantuvo una posición más bien "neutra", o bien directamente no estuvieron de acuerdo con que estudiaran una carrera universitaria. Esta última postura podría estar vinculada a una histórica preocupación de supervivencia en estos hogares.

Otra de las razones enunciadas en torno a su elección educativa actual, se vinculó al deseo de "ser alguien", de percibir al título universitario como aquello que los llevará a ascender socialmente, a tener un futuro mejor. Asimismo esta credencial pareciera funcionar, según el sentido que le atribuyeron los entrevistados, como una especie de "respaldo", una "garantía" para conseguir un trabajo. En este punto observamos algunas diferencias según el grado de vulnerabilidad que presentaban los jóvenes: quienes se encontraban inmersos en una situación de menor vulnerabilidad social, refirieron que el título universitario les aportaría posibilidades de "progresar", de "estar mejor"; mientras que entre aquellos jóvenes que presentaban una mayor vulnerabilidad social, se encontraba más extendida la noción de que con el título lograrían "ser alguien".

Asimismo, surgió del discurso de los jóvenes entrevistados como otra de las razones que los llevó a acceder a la educación superior universitaria el deseo de emanciparse, o al menos imbuirse en prácticas emancipatorias que los iniciaran en ese deseo. Con fines meramente analíticos optamos por desglosar los diversos tipos de emancipación identificados, decisión que no implica que los mismos no sean plausibles de darse de forma conjunta. A partir de este desglose nos encontramos con tres tipos de emancipaciones: la vinculada a la concreción de la independencia económica de sus familias, la referida a la emancipación habitacional (identificaron a la educación universitaria como una forma de salirse de sus lugares de origen, separarse del barrio) y la vincular (entendida como dejar de lado ciertos códigos relacionales que ya no comparten).

Por último la acumulación de capital social legitimado a partir de la generación de redes vinculares 
emergió como otra razón de inicio y permanencia en las universidades en tanto les permitió también, ya sea consciente o inconscientemente, obtener un mayor rendimiento del resto de los capitales, que, tal como mencionábamos anteriormente, los jóvenes objeto del presente estudio poseen en menor volumen.

Cabe observar que los aspectos vocacionales como razón aducida al inicio de la trayectoria universitaria, aparecieron muy poco en el discurso de estos jóvenes. En este sentido pareciera que lo vocacional se presenta algo desdibujado frente a una mayor preponderancia de las razones antes introducidas vinculadas a la salida y/o reducción del grado de vulnerabilidad social. Esta situación coincide con lo observado en un estudio realizado por Veleda (2002), quien indica que las razones vinculadas a la realización personal o vocacional, se encuentran mucho más ligadas a las expectativas de sectores medios-altos que a los jóvenes de sectores mediosbajos. En la misma línea, Tiramonti y Ziegler (2008) refieren que la valoración por el conocimiento y el saber es un factor decisivo en las elecciones educativas de los sectores sociales más favorecidos, sectores que incluso pueden considerar esas opciones como una vía para reforzar su capital económico y social ya adquirido.

Luego, al ahondar en torno a los factores que incidieron en la elección de estudiar en una institución universitaria determinada y no en otra, nos fue posible identificar que las principales dimensiones que tuvieron en cuenta al momento de elegir dónde estudiar correspondieron a la proximidad geográfica y al prestigio atribuido a la institución (no solamente vinculado a la calidad educativa, sino que también a las supuestas mayores posibilidades laborales). Estos aspectos pueden haber sido tenidos en cuenta, tanto para afirmar una elección, como para aseverar una "no elección". Destacamos que no todos los jóvenes entrevistados, ponderaron de la misma forma estas dimensiones, sino que justamente de allí deviene la diversidad y mixtura de las distintas trayectorias de los jóvenes. Así, por ejemplo, algunos observaron las grandes distancias geográficas a las universidades tradicionales como un elemento que desincentivó la posibilidad de asistir a las mismas, otros en cambio si bien consideraban la distancia como un factor que incidía negativamente en su trayectoria, aun así eligieron cursar en estas universidades más lejanas. Las universidades emplazadas en el GBA parecieron desde lo discursivo constituirse en "ofertas de proximidad", no sólo desde lo geográfico sino también instituciones que se acercan a los jóvenes, erigiéndolas como "algo posible".

Cabe introducir aquí algunos matices en torno a los desarrollos teóricos vinculados a las trayectorias universitarias. Tinto (1989) sostiene en torno a las razones de inicio y permanencia de los jóvenes en la universidad, que un número sorprendentemente grande de estudiantes que ingresan a la universidad tienen una idea poco clara acerca de las razones por las cuales inician su trayectoria. El autor refiere que éstos parecen no haber reflexionado seriamente sobre la elección de la institución en la que realizarán sus estudios superiores, remarca incluso que para muchos egresados de las escuelas del nivel educativo medio, el proceso de elegir universidad es notablemente fortuito, a menudo basado en información insuficiente. Por su parte, Panaia (2013) afirma que la mayoría de los jóvenes parece no tener una decisión precisa de continuar los estudios universitarios, salvo en casos en los que haya un fuerte mandato familiar o un proyecto definido en metas muy precisas. $\mathrm{Al}$ parecer, lo anterior no se corroboraría entre los jóvenes participantes de nuestra investigación, en tanto entre ellos parecen primar explícitamente nociones vinculadas a la movilidad social ascendente y a la posibilidad de emanciparse, verificándose la existencia de un deseo íntimo y compartido de salir de la situación de vulnerabilidad, salida que se vislumbra más próxima con un título universitario en mano, dando cuenta de una particular forma de procesar las desigualdades sociales en nuestro país. 
A modo de reflexión quisiéramos presentar una categorización introducida por Veleda (2002), quien refiere a una valoración construida en torno al nivel universitario y terciario identificando a los mismos como "estudios de primera y de segunda" respectivamente. Los "de primera" parecían posibilitar una mejor inserción laboral, permitir una formación más amplia, de mejor calidad y adquirir mayor prestigio social. Por el contrario, las instituciones terciarias aparecían descritas como instituciones "de segunda" en tanto las percibían como aquellas que parecen otorgar menores posibilidades laborales y de progreso. Al poner a jugar estas categorías en nuestra investigación, nos fue posible identificar también en el discurso de los entrevistados referencias a "estudios de primera y de segunda" pero ya no vinculado a los niveles de enseñanza sino a las instituciones universitarias. Esto en tanto pareciera que hay instituciones que son elegidas en primera instancia y otras en una segunda instancia. Si bien esta situación no se dio en todos los entrevistados, entre quienes sí atravesaron un proceso de "ponderación" de las instituciones, los argumentos en torno a la elección de las instituciones seleccionadas en primera instancia refieren por lo general al mayor prestigio percibido, mejores posibilidades de trabajo luego de recibidos o bien a un mayor conocimiento derivado de una superior antigüedad de esas casas de estudio. Por su parte, en la elección de las instituciones de segunda instancia pareciera tener más importancia la cercanía a sus hogares, ésto en tanto factores como ver reducido su tiempo de sueño, de estudio, entre otros, son elementos que pueden desalentar el ingreso y/o permanencia en las universidades que eligieron como primera opción. Entre los entrevistados suelen coincidir que las instituciones de primera son asimiladas a las universidades tradicionales y las de segunda a las "nuevas universidades". Cabe destacar que esta atribución de sentido diferencial es plausible de verse modificada en el tiempo y es en este punto sobre el que nos interesa profundizar. 


\section{Referencias}

Ball, S. (2003), Class strategies and the education market. The middle classes and social advantage, Londres, Routledge Falmer.

Borja, J. y M. Castells (2000), Localy global. La gestión de las ciudades en la era de la información, México, Taurus Ediciones.

Bourdieu, P. (1985), "The forms of capital", en J. G. Richardson (ed.), Handbook of theory and research for the sociology of education, Nueva York, Greenwood.

Bourdieu, P. (1988), La distinción. Bases y criterios sociales del gusto, Buenos Aires, FGE.

Brunner, J. J. (2012), "La idea de universidad en tiempos de masificación", en Revista Iberoamericana de Educación Superior (RIES), México, UNAM-IISUE/Universia, Vol. III, núm. 7, pp. 130-143, <http://ries.universia. net/ index.php/ries/article/view/228> [consulta: 9 de mayo de 2016].

Buchbinder, P. (2005), Historia de las universidades argentinas, Buenos Aires, Sudamericana.

Bustos, J. M., F. Sciarrotta y S. Ticera (2001), "Clima educativo e ingreso de los hogares: encuentros y desencuentros en los últimos diez años", en Laboratorio, Informe de coyuntura laboral, Año 3, Núm. 7, Primavera 2001, <http://www.aacademica.com/agustin.salvia/96. pdf $>$ [consulta: 06 de septiembre de 2014].

Carli, S. (2012), El estudiante universitario: hacia una historia del presente de la educación pública, Buenos Aires, Siglo Veintiuno Editores.

Castel, R. (1997), La metamorfosis de la cuestión social, Buenos Aires, FCE.

Chiroleu, A. (2013), "Políticas públicas de educación superior en América Latina: ¿democratización o expansión de las oportunidades en el nivel superior?, en Espacio Abierto, 22(2), pp. 279-304, <http://www. redalyc.org/pdf/122/12226914006.pdf> [consulta: 13 de enero de 2015].

Chiroleu, A. y M. Marquina (2012), "Tiempos interesantes: complejidades, contradicciones e incertidumbre de la política universitaria actual", en A. Chiroleu, M. Marquina y E. Rinesi (comps.), La política universitaria de los gobiernos Kirchner: continuidades, rupturas, complejidades, Buenos Aires, Universidad Nacional de General Sarmiento.

Comisión Económica para América Latina y el Caribe (CEPAL, 1992), Educación y Conocimiento: eje de la transformación productiva con equidad, Santiago de Chile, Oficina Regional de Educación de la UNESCO para América Latina y el Caribe (OREALC).

Dussel, I. (2010), La escuela media argentina y los desafios de las metas 2021, <http://www.fundacionsantillana.org/ upload/ficheros/noticias/201007/libro_v_foro.pdf> [consulta: 26 de marzo de 2014].

Dussel, I. (2005), "Desigualdades sociales y desigualdades escolares en la Argentina de hoy. Algunas reflexiones y propuestas", en J. C. Tedesco (comp.), ¿Cómo superar la fragmentación del sistema educativo argentino?, Buenos Aires, IIPE-UNESCO Ediciones.

Ezcurra, A. M. (2011), Igualdad en educación superior. Un desafio mundial, Buenos Aires, UNGS, IEG-CONADU [Serie Universidad. Los Polvorines].

Ezcurra, A. M. (2009), Educación universitaria: una inclusión excluyente, Buenos Aires, Fundación IDEAS.

Fernández Lamarra, N. (2015) "El desarrollo de la educación superior en América Latina en perspectiva comparada", en A. Otero y M. C. Corrochano (comps.), Educación superior en perspectiva comparada y regional, Buenos Aires, Flacso/Teseo.

García de Fanelli, A. (2015), "La cuestión de la graduación en las universidades nacionales de la Argentina: indicadores y políticas públicas a comienzos del siglo XXI", en Propuesta Educativa, 43 (24), pp. 17-31.

García de Fanelli, A. (2005), Acceso, abandono y graduación en la educación superior argentina, SITEAL, IIPE-UNESCO.

Giddens, A. (1995), La constitución de la sociedad: bases para la teoría de la estructuración, Buenos Aires, Amorrortu.

Giddens, A. (1987), Las nuevas reglas del método sociológico, Buenos Aires, Amorrortu. 
Hernández, G. y L. Garbarini (2010), "El estado benefactor y la expansión del sistema educativo en Argentina", en D. Toribio (comp.), La universidad en la Argentina: miradas sobre su evolución y perspectivas, Buenos Aires, Universidad Nacional de Lanús, Departamento de Planificación y Política Pública.

INDEC (2003), ¿Qué es el Gran Buenos Aires?, Buenos Aires, Instituto Nacional de Estadísticas y Censos, <http:// www.indec.mecon.ar / nuevaweb/cuadros / 4 / folleto $\% 20 \mathrm{GBA} . p d f>$ [consulta: 13 de abril de 2014].

Jacinto, C. (2008), "Políticas públicas y perspectivas subjetivas en torno a la transición laboral de los jóvenes", en M. Novick, G. P. Sosto y L. M. Archaga, El estado y la reconfiguración de la protección social: asuntos pendientes, Buenos Aires, Instituto Di Tella.

Jacinto, C. (1997), "Políticas públicas de capacitación laboral de jóvenes en Argentina: un análisis desde las expectativas y las estrategias de los actores", en Boletín Cinterfor, núm. 139, pp. 57-88, Montevideo.

Kessler, G. y V. Espinoza (2003), "Movilidad social y trayectorias ocupacionales en Argentina: rupturas y algunas paradojas del caso de Buenos Aires", en Serie Políticas Sociales, 66, División de Desarrollo Social, CEPAL ECLAC, Santiago de Chile, <http://www. cepal.org/publicaciones/xml/4/12504/lcl1895e-p. pdf $>$ [consulta: 06 de septiembre de 2014].

Mayer, L. (2012), "La conflictividad escolar cotidiana. Un estudio cualitativo de las estrategias para su prevención y/o minimización", Tesis de Doctorado en Ciencias Sociales.

Mendoza-Rojas, Javier (2015), "Ampliación de la oferta de educación superior en México y creación de instituciones públicas en el periodo 2001-2012”, en Revista Iberoamericana de Educación Superior (RIES), México, UNAMIISUE/Universia, vol. VI, núm. 16, <https://ries.universia. net/article/view/1135/ampliacion-oferta-educacionsuperior-mexico-creacion-instituciones-publicasperiodo-2001-2012> [consulta: 02 de mayo de 2016].
Montes, N. (2004), "Adolescentes y jóvenes en contexto. El marco cercano: la familia y el marco amplio: los otros", en G. Tiramonti (comp.), La trama de la desigualdad educativa. Mutaciones recientes en la escuela media, Buenos Aires, Manantial.

Montes, N.y M.A. Sendón(2010), “Trayectorias educativas de adolescentes en una Argentina fragmentada", SECYT, http://www. anped. org. br. [Consulta: 26 de abril de 2014].

Panaia, M. (2013), "Abandonar la universidad: ¿decisión premeditada o imprevista?, en M. Panaia (coord.), Abandonar la universidad con o sin título, Buenos Aires, Miño y Dávila.

Pérez Rasetti, C. (2012), "La expansión de la educación universitaria: políticas y lógicas", en A. Chiroleu, M. Marquina y E. Rinesi (comps.), La política universitaria de los gobiernos Kirchner: continuidades, rupturas, complejidades, Buenos Aires, Universidad Nacional de General Sarmiento.

Petracci, M. (2007), "La agenda de la opinión pública a través de la discusión grupal. Una técnica de investigación cualitativa: el grupo focal”, en A. L. Kornblit (coord.), Metodologías cualitativas en ciencias sociales. Modelos y procedimientos de análisis, Buenos Aires, Editorial Biblos.

Pochulu, M. (2004), "La educación superior argentina hoy, entre instituciones que se transforman y relaciones que se modifican", en Revista Iberoamericana de Educación (ISSN: 1681-5653).

Progré, P. (2015), "Pensar la enseñanza en el nivel superior en clave regional", en A. Otero y M. C. Corrochano (comps.), Educación superior en perspectiva comparada y regional, Buenos Aires, FLACSO/Teseo.

Prost, A. (1986), L'enseignement s'est-il démocratisé?, París, PUF.

Secretaría de Políticas Universitarias (SPU), Anuarios de Estadisticas Universitarias 2011, 2010, 2006 y 2004, Buenos Aires, SPU, Ministerio de Educación. 
Sigal, V. (1995), El acceso a la educación superior, Buenos Aires, SPU [Serie Estudios y Propuestas], Ministerio de Cultura y Educación.

Terigi, F. (2007), "Los desafíos que plantean las trayectorias escolares", ponencia presentada en el III Foro Latinoamericano de educación. Jóvenes y docentes. La escuela secundaria en el mundo de hoy, Fundación Santillana.

Tinto, V. (1989), "Definir la deserción: una cuestión de perspectiva", en Revista de Educación Superior, núm. 71. pp.33-51, <http://preu.unillanos.edu.co/sites/default/ files/fields/documentos/vicen $\% 20$ tinto $\% 20$ deser.pdf> [consulta: 18 de junio de 2014].

Tiramonti G. y S. Ziegler (2008), La educación de las elites. Aspiraciones, estrategias y oportunidades, Buenos Aires, Paidós.

Tiramonti, G. y N. Montes (2008), “Trayectorias educativas y laborales: un cruce desde la percepción de estudiantes del nivel medio", en G. Tiramonti (comp.), La escuela media en debate, Buenos Aires, Manantial.

Toribio, D. (2010), "La expansión de la educación superior en contextos de crisis sociales y políticas", en D. Toribio (comp.), La universidad en la Argentina: miradas sobre su evolución y perspectivas, Buenos Aires, Universidad Nacional de Lanús, Departamento de Planificación y Política Pública.

Torrado, S. (2003), Historia de la familia en la Argentina moderna (1870-2000), Buenos Aires, Ediciones de la Flor. Torrado, S. (1981), "Sobre los conceptos de 'estrategias familiares de vida' y 'proceso de reproducción de la fuerza de trabajo': Notas teórico-metodológicas", en Demografia y economía, pp. 204-233, México, Colegio de México.

Torres, H. (1998), Procesos recientes de fragmentación socioespacial en Buenos Aires: la suburbanización de las elites, Buenos Aires, CONICET, FADU-UBA.

Uthoff A. y L. Beccaria L. (2007), Panorama social de América Latina. Transmisión de las oportunidades educativas 2007, Santiago de Chile, División de Desarrollo Social y la División de Estadística y Proyecciones, Económicas, ONU, GEPAL, <http//www.eclac.org/publicaciones/ xml> [Consulta: 29 de marzo de 2014].

Veleda, C. (2002) "Estrategias individuales y familiares en la elección de las instituciones de educación superior" en M. Kiliseuvsky y C. Veleda, Dos estudios sobre el acceso a la educación superior en Argentina, Buenos Aires, IIPEUNESCO, <http://www.buenosaires.iipe.unesco.org/ sites/default/files/kisilevsky-veleda.pdf> [consulta: 04 de abril de 2013].

Weber, M. (1965), Essais sur la théorie de la science, París, Plon. Ziccardi, A. (2001), "Las ciudades y la cuestión social", en A. Ziccardi (comp.), Pobreza, desigualdad social y ciudadanía. Los límites de las políticas sociales en América Latina, Buenos Aires, GLACSO.

Cómo citar este artículo:

Cerezo, Leticia (2018), "El ingreso a la universidad de jóvenes en situación de vulnerabilidad social: razones y factores que los motivan", en Revista Iberoamericana de Educación Superior (RIES), México, UNAM-IISUE/ Universia, vol. IX, núm. 25, pp. 62-84, http://DX.DOI.ORG/10.22201/IISUE.20072872E.2019.25.339 [consulta: fecha de última consulta]. 